\title{
Em ação, uma celebridade-resistência: Preta Gil e os valores contemporâneos ${ }^{1}$
}

\section{In action, a celebrity-resistance: Preta Gil and the contemporary values}

Dayana Cristina Barboza Carneiro² e Paula Guimarães Simões ${ }^{3}$ Desenvolvimento Científico e Tecnológico (CNPq), à Fundação de Amparo à Pesquisa do Estado de Minas Gerais (Fapemig) e à Pró-Reitoria de Pesquisa da Universidade Federal de Minas Gerais (UFMG) pelo apoio ao desenvolvimento de nossas pesquisas. Pesquisadora do Grupo de Pesquisa em Imagem e Sociabilidade (GRIS). E-mail: barboza.dayana@gmail.com. 


\section{Resumo}

O objetivo deste texto é analisar como a dimensão acontecimental de uma figura pública (e seu poder hermenêutico) pode configurá-la como o que nomeamos celebridade-resistência, contrapondo-se a opressões sociais e evidenciando valores progressistas. Para tanto, exploramos a trajetória da cantora Preta Gil a partir de uma abordagem pragmatista, tendo em vista ações materializadas em seu perfil no Instagram. Além disso, assumimos uma abordagem interseccional para apreender em que medida valores vigentes no contexto contemporâneo emergem e se articulam com essa celebridade. A análise identifica três eixos de subordinação - raça, peso e sexualidade - associados à imagem pública de Preta, fortemente arraigada à dimensão do enfrentamento e da resistência.

\section{Palavras-chave}

Acontecimento, celebridade-resistência, valores, poder hermenêutico, Preta Gil.

\section{Abstract}

This paper aims to analyze how the event dimension of a public figure (and its hermeneutic power) can set them up as what we call a celebrityresistance, opposing social oppression and showing progressive values. Therefore, we explore the trajectory of the singer Preta Gil from a pragmatic approach, considering actions materialized in her profile on Instagram. In addition, we assume an intersectional approach, to apprehend to which extent the current values in the contemporary context emerge and articulate with this celebrity. The analysis identifies three axes of subordination - race, weight, and sexuality associated with Preta's public image, strongly rooted in the dimension of confrontation and resistance.

\section{Keywords}

Event, celebrity-resistance, values, hermeneutic power, Preta Gil. 


\section{Introdução}

Preta Maria Gadelha Gil Moreira de Godoy (@pretagil) é uma cantora, atriz e apresentadora brasileira. Desde muito cedo ocupou a cena pública, por ser filha do cantor Gilberto Gil, e hoje atua também como influenciadora digital, com cerca de 8,7 milhões de seguidores no Instagram4. Em suas publicações, além da divulgação do trabalho, compartilha com os seguidores sua rotina como mãe, avó e esposa, e aborda questões relacionadas ao racismo, à diversidade de corpos e à defesa da igualdade e da diversidade.

O objetivo deste texto é refletir sobre esse percurso de vida de Preta Gil e o modo como podemos apreendê-la como uma "celebridade-acontecimento" (SIMÕES, 2014a), na medida em que traços, princípios e valores da sociedade contemporânea podem emergir a partir da sua trajetória. Tendo em vista esse poder hermenêutico de uma celebridade e adotando uma abordagem pragmatista e interseccional, procuramos refletir sobre essa figura pública como uma celebridade-resistência, ou seja, uma celebridade que se opõe a opressões vigentes na sociedade brasileira. De modo específico, voltamos nosso olhar para três eixos de subordinação vinculados à figura de Preta Gil: raça, peso e sexualidade.

Assim, o texto está dividido em três partes, além das considerações finais. $\mathrm{Na}$ primeira, discutimos o conceito de acontecimento a partir de uma visada pragmatista e mostramos como refletir sobre a dimensão acontecimental de uma celebridade. Na segunda, abordamos a relação entre celebridades e valores sociais, evidenciando como o estudo acerca de uma figura pública pode revelar traços da sociedade em que se inscreve. Na terceira, realizamos a análise de Preta Gil, a partir de ações que podem ser apreendidas em seu perfil do Instagram, seguindo os três eixos destacados acima. 


\section{O acontecimento como "uma" experiência}

Partindo da compreensão de que a perspectiva acontecimental adotada neste trabalho é aquela proposta por Quéré (2012), que tem, como base teórica, o Pragmatismo, empreendemos a tentativa de fazer o caminho inverso: compreender de que maneira e em que medida as principais dimensões do acontecimento 5 já se faziam presentes na noção de "uma" experiência em Dewey (1980). Sendo assim, apesar de sabermos que o acontecimento não se constitui como sinônimo de

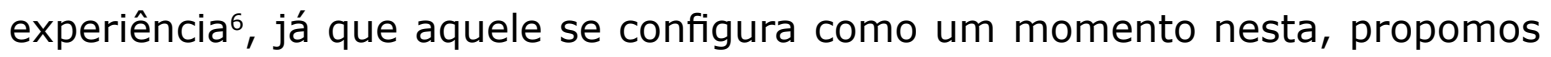
pensar, ainda que de maneira incipiente, de que forma é possível identificar na concepção de "uma" experiência (DEWEY, 1980) traços constituidores da noção de acontecimento.

Ao conceituar experiência, Dewey (1980) afirma que: "o esquema padrão do comum é dado pelo fato de que toda experiência é o resultado da interação entre uma criatura viva e algum aspecto do mundo no qual ela vive" (DEWEY, 1980, p. 95), dinâmica que evidencia a dimensão interacional da experiência. Por esse viés, explica Simões (2014b), a experiência se constitui por meio da articulação entre o "agir e o reagir", entre o "produzir e o sofrer". Nesse processo, há uma transformação mútua do sujeito e do mundo com o qual ele interage.

No entanto, esse papel transformador não está presente em todas as experiências, e é a partir desse entendimento que Dewey (1980) constrói uma diferenciação que irá fundamentar as suas reflexões: a diferença entre experiência e o que ele nomeia de "uma" experiência. A primeira marcada por uma característica mais superficial e incipiente (LANA et al., 2014), e a segunda entendida como uma experiência mais profunda, "completa", que se desloca 
em direção a uma transformação e, para isso, se afasta da ideia de repetição e da mecanicidade (DEWEY, 1980). Ou seja, constitui-se a partir de um processo de reflexividade, que transforma quem o vivenciou e leva a uma reorientação de conduta.

Da mesma maneira que a experiência, o acontecimento também pode ser compreendido a partir de duas instâncias não-dicotômicas. Ele é dotado de uma dupla vida (QUÉRÉ, 2012): desloca-se de um acontecimento existencial para um acontecimento-objeto. No primeiro caso, o acontecimento liga-se à dimensão concreta da experiência (SIMÕES, 2014b) e articula-se a reações imediatas e hábitos: o sujeito reage sem que o acontecimento se torne um objeto de estudo ou seja distanciado de seu contexto (QUÉRÉ, 2012). Já o acontecimento-objeto está relacionado à esfera simbólica do acontecimento, que é constituído a partir dos processos de descrição e narrativização. "Passando pelo processo de simbolização, essa forma de acontecimento ganha uma dimensão discursiva e passa a fazer parte da organização de nossa conduta" (SIMÕES, 2014b, p. 185).

A dimensão da revelação no acontecimento origina-se a partir do seu poder hermenêutico, que diz sobre a capacidade de romper com a linearidade dos sentidos e instaurar novos dizeres possíveis. De acordo com Quéré:

Os acontecimentos se tornam, eles próprios, fonte de sentido, fonte de compreensão e fonte de redefinição da identidade daqueles que afetam. Nessa perspectiva, em que o acontecimento vem antes dos sujeitos e das situações, é o que ele se torna através de seu percurso, e os efeitos de sentido que produz, que contribuem para individualizá-lo. É nesse sentido que se pode falar de um poder hermenêutico do acontecimento. (QUÉRÉ, 2010, p. 35)

Sob a perspectiva hermenêutica do acontecimento, "[...] a criação de fatos apenas se traduz em acontecimento se eles conseguem inscrever no horizonte de sentidos possibilidades que não estavam dadas anteriormente" (FRANÇA, 2012b, p. 46). Nesse contexto, o poder hermenêutico tem a capacidade de fomentar processos de descoberta e de desvelar sentidos sobre quadros valorativos da nossa sociedade. 
Acontecimento, numa perspectiva pragmatista, refere-se a uma ocorrência, um fato concreto do cotidiano com grande poder de afetação, que suscita inquietações, demanda escolhas e provoca ações, este fato convoca e revela sentidos, que dizem da sociedade na qual ele ocorre. (FRANÇA; LOPES, 2017, p. 73-74)

No acontecimento, junto ao poder hermenêutico, constitui-se o poder de afetação dos sujeitos, o que revela a sua passibilidade (QUÉRÉ, 2005): os sentidos gerados a partir do acontecimento afetam os sujeitos, e vice-versa (SIMÕES, 2014b). Também no conceito de experiência é possível vislumbrar a dimensão da afetação a partir da articulação entre o fazer e o sofrer.

Como se verá mais tarde, há em toda experiência um elemento de padecimento, de sofrimento, em sentido amplo. De outra maneira não haveria incorporação vital, é algo mais do que colocar algo sobre a consciência, sobre o previamente conhecido. Implica uma reconstrução que pode ser penosa. (DEWEY, 1980, p. 93)

Dessa forma, para que a experiência se constitua como "uma" experiência, é necessário que haja um engajamento dos sujeitos por meio do qual pode se constituir um processo de transmutação no âmbito do sujeito e do seu ambiente.

Nestes termos, o potencial transformador da experiência se realiza na vocação ativa dos indivíduos para a intervenção objetiva no mundo, por meio da comunicação social e das múltiplas possibilidades de transação que esta Ihes oferece. (LANA et al., 2014, p. 147)

Para Quéré (2012, p. 21), acontecimento "é o que vem de fora, o que surge, o que acontece, o que se produz, o excepcional que se desconecta da duração". Essa afirmação dá relevo a outra questão central no conceito de acontecimento: a dimensão da temporalidade. A partir da articulação entre passado, presente e futuro, um "universo de sentidos" é desencadeado (SIMÕES, 2014b). A emergência e as reverberações geradas a partir de um acontecimento - uma desorganização - alteram as possibilidades de leitura do passado com o qual ele se associa e anuncia "futuros possíveis" (FRANÇA, 2012b, p. 47). 
Tal mudança implica uma heterogeneidade interna e um movimento direcional: por um lado, não há a mesma coisa de um extremo a outro do processo: por outro, é impossível perceber um devir se não for apreendida uma transição de um estado para outro, passando por um ou vários estados intermediários. (QUÉRÉ, 2012, p. 26)

De modo análogo, uma experiência também se constitui a partir de uma relação entre passado-presente-futuro. É essa conexão entre o ocorrido, o que sucedeu e o que virá que confere qualidade estética à experiência, condição sine qua non para a constituição de "uma" experiência.

Em uma experiência, o fluxo vai de algo a algo. Como uma parte conduz a outra, e como outra parte traz aquela que veio antes, cada uma ganha distinção em si própria. O todo permanente é diversificado em fases sucessivas que constituem ênfases de seus variados matizes. (DEWEY, 1980, p. 90)

Assim, para que se tenha "uma" experiência, é preciso que haja uma construção de sentidos que transcende o resultado em si próprio, o que dá relevo à dimensão da qualidade estética nesse processo: "o que distingue uma experiência como estética é a conversão das resistências e das tensões, das excitações que em si próprias são tentações para a dispersão, em um movimento dirigido para um término inconclusivo e satisfatório" (DEWEY, 1980, p. 105).

Considerando a reflexão empreendida até aqui, podemos aventar que já existia ali no conceito de "uma" experiência em Dewey (1980) as bases fundamentais para a construção da noção de acontecimento - que o próprio autor desenvolverá. Nesse sentido, reforça-se o caráter pragmatista da perspectiva de Quéré (2012) que, a partir da articulação com outros autores, concebeu a noção de acontecimento que acionamos neste artigo ${ }^{7}$.

Partimos, agora, para a abordagem da temática das celebridades: como pensar em uma dimensão acontecimental das figuras públicas e em seu poder hermenêutico? Procuramos enfatizar o modo como essas personalidades 
de referência podem acionar sentidos relacionados a determinados quadros valorativos na contemporaneidade e, assumindo um lugar de oposição e enfrentamento a opressões sociais, podem se configurar como o que nomeamos celebridade-resistência.

\section{Celebridades, valores e sociedade}

Neste trabalho, as celebridades são entendidas a partir dos sentidos que elas evocam: "conhecimento, reconhecimento, culto. Diz de alguém que se torna conhecido por muitas pessoas, reconhecido por aquilo que é ou faz, cultuado enquanto uma certa excepcionalidade digna de admiração e reverência" (FRANÇA, 2014, p. 19). Apesar da complexidade do processo de constituição das celebridades, em que estão envolvidos fatores socioculturais e midiáticos, é possível pensar em dimensões elementares que atuam na configuração desse fenômeno e que geram visibilidade, valor fundamental para a atuação das celebridades na contemporaneidade.

Grosso modo, celebridades se constituem a partir de três fundamentos: as qualidades que ostentam, o lugar institucional que ocupam, sua presença/participação em algum acontecimento de destaque. Tais aspectos são geradores de visibilidade; a visibilidade, se bem aproveitada, proporciona a fama, desperta sentimentos de adesão ou rejeição. (FRANÇA; SIMÕES, 2020, p. 5)

A respeito dessa temática, Simões (2009) afirma que a função da mídia não se restringe a oferecer visibilidade às celebridades: ela também se constitui como instância ativa no seu processo de construção. Sendo a mídia uma mediadora das práticas sociais e de seus processos de significação, não é possível falar em celebridades pré-existentes, uma vez que a sua formação se dá a partir da interação que se configura entre "as 'estrelas em potencial', os indivíduos na vida cotidiana, a mídia e o contexto social" (SIMÕES, 2009, p. 75).

No entanto, a instância midiática é uma das variáveis - e não a única ou determinante - no processo de construção dos sujeitos enquanto celebridades: 
"[...] rejeitamos uma perspectiva monocausal, e indicamos o risco dos argumentos deterministas - como se a mídia, por si só, fosse dotada de um toque de Midas" (FRANÇA, 2014, p. 21). Com base nessa abordagem relacional, o estudo sobre as figuras públicas não deve estar ancorado apenas na abordagem da celebridade em si, mas na maneira como esse sujeito pode nos dizer algo sobre a sociedade.

Assim, é preciso voltar o olhar para os valores que essas celebridades evocam e de que modo isso nos permite inferir sobre os traços, princípios e crenças que compartilhamos socialmente: quais aspectos de nossa sociedade são personificados por essa figura pública.

\footnotetext{
Destaca-se, assim, tanto a dimensão individual das celebridades (capazes de interpelar a sociedade a partir de determinados atributos) como a dimensão coletiva e social das mesmas: é a partir da sintonia com o quadro de valores em certo momento que as celebridades conseguem, de alguma forma, construir vínculos com os sujeitos na vida social. (FRANÇA; SIMÕES, 2014, p. 1078)
}

Para que um indivíduo se torne celebridade, é necessário que, em algum momento, haja um sincronismo entre o que ele representa e os valores compartilhados na/pela sociedade. Nesse viés, a constituição do sujeito como celebridade se dá a partir de processos que podem ser compreendidos por meio da identidade e da diferença. "O ídolo, a celebridade nos atrai pelo que nos assemelha, pela força do mesmo. Outras vezes, é exatamente a distância, o estranhamento que ele nos provoca enquanto 'outro' que nos fascina e nos convoca" (FRANÇA, 2014, p. 27). No âmbito da identidade estão inscritos os processos de projeção e idealização do sujeito, o que há de comum e o que é compartilhado. Já a instância da diferença faz emergir a dimensão do outro "[...] que não apenas confirma o nosso lugar, mas indica a existência de lugares diversos" (FRANÇA, 2014, p. 28).

Assim, as figuras públicas de referência que se constituem em relação ao contexto social - específico e amplo - no qual estão inseridas nos permitem pensar sobre os valores sociais vigentes e, consequentemente, dizem-nos muita coisa sobre o momento social em que se estabelecem. 
No entanto, é interessante registrar que tais figuras devem ser compreendidas não (apenas) por características intrínsecas de alguns indivíduos, o que significaria uma personalização do fenômeno, ou através de uma explicação psicossocial (necessidade e busca de um líder), mas, sobretudo, pelo viés social - por sua ligação às tendências e às configurações de poder nas sociedades nas quais se destacam. O fenômeno, portanto, é universal, mas as celebridades são históricas e refletem o contexto em que surgem. (FRANÇA; SIMÕES, 2020, p. 3-4)

É partindo dessa articulação entre celebridades e contextos sociais que podemos perceber a dimensão acontecimental dessas figuras, ou seja, no modo como podem se configurar celebridades como acontecimentos (SIMÕES, 2014a).

\begin{abstract}
Assim, entendidas como acontecimentos, as celebridades também são vistas como fonte de sentido para a compreensão do mundo. Dessa forma, em virtude de seu poder hermenêutico, as celebridades permitem-nos compreender traços e valores do campo específico em que elas se situam e da sociedade em que se inscrevem (e que ajudam a construir). (SIMÕES, 2014a, p. 47)
\end{abstract}

Como explica Simões (2014a), é o poder hermenêutico da celebridade que revela a sua "dimensão acontecimental" e nos permite articular o modo como essa figura pública de referência pode desvelar valores sociais e, assim, dizer algo sobre nossa sociedade.

Algumas celebridades, assim, ao emergirem na cena pública, instauram uma descontinuidade a partir dos valores que defendem, das pautas em que se engajam e do modo como conseguem desencadear discussões acerca de questões de interesse comum. Assim, essas figuras públicas de referência "promovem conexões sociais importantes, capazes de fazer reverberar de diversas maneiras os discursos 'dominantes' e os discursos de minorias" (MEDEIROS, 2016, p. 161).

Nesse sentido, entendemos que a dimensão acontecimental de uma figura pública (e seu poder hermenêutico daí decorrente) pode configurá-la como o que nomeamos celebridade-resistência: uma personalidade que se contrapõe a diferentes tipos de opressão social, evidenciando valores progressistas e emancipatórios comprometidos com a igualdade, o respeito e a justiça social. É essa proposta, 
que aciona a dimensão acontecimental e o poder hermenêutico para pensar em uma celebridade-resistência, que orienta a análise que realizamos neste artigo.

\section{O que Preta Gil pode dizer sobre nossa sociedade: um olhar interseccional}

A abordagem metodológica adotada neste artigo conjuga o viés pragmatista para análise das celebridades com um olhar interseccional. A abordagem pragmatista se volta para as ações empreendidas pelas figuras públicas em um contexto social, ou seja, para o lugar da experiência delas no cenário de visibilidade (FRANÇA; SIMÕES, 2020).

Preta Gil é negra, gorda e declaradamente pansexual ${ }^{8}$. Sua trajetória e constituição como sujeito e celebridade passa pela vinculação a grupos socialmente minoritários. Todos esses aspectos se imbricam na formação de sua imagem pública ${ }^{9}$ e, consequentemente, no modo como ela se aproxima de determinados traços ou valores de nossa sociedade. Diante disso, acreditamos que se deve olhar para essa celebridade tendo em perspectiva a dimensão da interseccionalidade.

Assim como é verdadeiro o fato de que todas as mulheres estão, de algum modo, sujeitas ao peso da discriminação de gênero, também é verdade que outros fatores relacionados a suas identidades sociais, tais como classe, casta, raça, cor, etnia, religião, origem nacional e orientação sexual, são "diferenças que fazem diferença" na forma como vários grupos de mulheres vivenciam a discriminação. (CRENSHAW, 2002, p. 173)

Dessa maneira, interessa observar a interação entre essas "avenidas de opressão" - raça, peso, sexualidade, idade, gênero, classe, geolocalização e deficiência (CARRERA, 2021) - e o modo como as combinações desses recortes,

Disponível em: https://bit.ly/3DPkJxz. Acesso em: 8 abr. 2021. Pansexualidade é a atração sexual, romântica ou emocional em relação às pessoas, independentemente de seu sexo ou da identidade de gênero. 
que se constituem de maneira particular em cada caso, podem ser identificadas e tensionadas a partir da trajetória de Preta Gil.

Para operacionalização desta análise, daremos destaque aos eixos de raça, peso e sexualidade - tendo em vista também a questão de gênero que os perpassa. A intenção é revelar os valores dos quais essa celebridade se aproxima ou se distancia - ou em relação aos quais ela assume uma posição de enfrentamento - e o modo como esses valores se articulam com suas "diferenças".

Assim, essa abordagem pragmatista e interseccional incide sobre a trajetória de Preta Gil de forma mais ampla, recorrendo a acontecimentos marcantes na constituição de sua face pública ${ }^{10}$. Para uma análise mais específica, definimos um corpus composto de posts publicados em sua rede social Instagram, tendo como recorte temporal da investigação o período de 25 de maio a 28 de agosto de 2020, que compreende a data do assassinato de George Floyd até o falecimento de Chadwick Boseman, dois acontecimentos que marcaram a luta antirracista em 2020 - uma pauta importante na trajetória da celebridade analisada.

Nesse intervalo de tempo, a cantora fez 17 posts com temática racial, o que corresponde a $11,8 \%$ do total de 144 publicações - configurando um primeiro eixo de análise das ações da celebridade analisada. Um segundo eixo se refere à questão do peso: foram nove publicações com essa temática, o que corresponde a $6,2 \%$ do total de postagens. Um terceiro eixo de análise diz respeito à sexualidade: no período analisado, houve um post que tratava da luta LGBTI+. Esses três eixos serão abordados a seguir, tendo em vista o olhar interseccional apresentado anteriormente. E, a partir deles, procuramos destacar os valores agregados à face pública de Preta Gil.

Assim, um primeiro aspecto que se pode evidenciar na trajetória de Preta é a questão da raça. A luta pela igualdade racial se coloca, primeiramente, no próprio nome da cantora. Em entrevista ${ }^{11}$, ela e o pai contaram o estranhamento 
causado no cartório ao revelar a escolha do nome "Preta" para a filha. Diante do questionamento da tabeliã, Gil argumentou que os prenomes Branca e Clara eram usuais e sugeriu a inclusão do segundo nome "Maria" na certidão de nascimento como solução para o óbice.

Outro acontecimento marcante, que evidencia o modo como a dimensão da raça se faz presente na constituição de Preta Gil como sujeito e celebridade e, consequentemente, conforma os valores aos quais ela está associada, é a pergunta que ela fez a Jair Bolsonaro ${ }^{12}$ no extinto programa da Band, Custe o Que Custar (CQC), em 2011, no quadro "O povo quer saber": "Se seu filho se apaixonasse por uma negra, o que você faria?". Em resposta, o então deputado federal pelo Rio de Janeiro afirmou: "eu não vou discutir promiscuidade com quem quer que seja. Eu não corro esse risco. Meus filhos foram muito bem educados e não viveram em um ambiente como, lamentavelmente, é o seu".

Diante do comentário racista, a cantora se manifestou em seu Twitter: "Advogado acionado, sou mulher Negra, forte e irei até o fim contra esse Deputado, Racista, Homofóbico, Nojento, conto com o apoio de vocês". Em 2015, o Supremo Tribunal Federal (STF) arquivou o inquérito que apurava se houve racismo contra a cantora ${ }^{13}$. No entanto, recentemente, em 2019, o Tribunal de Justiça do Rio de Janeiro (TJ-RJ) manteve a penalização de Bolsonaro pelas mesmas declarações feitas em 2011, incluindo, também, as homofóbicas. Ele foi condenado a pagar 150 mil reais por danos morais ao Fundo de Defesa dos Direitos Difusos (FDDD), do Ministério da Justiça ${ }^{14}$.

A cantora mantém esse posicionamento de enfrentamento ao racismo nos dias atuais. Recentemente, em 2019, lançou o seu primeiro monólogo autobiográfico e musical, "Mais Preta Que Nunca", anunciado por meio da seguinte mensagem: "[...] mais conectada à minha ancestralidade, mais consciente de quem sou, 
em paz com meu passado e pronta para novos desafios!!!". Em seu perfil no Instagram, denuncia casos de racismo e assassinato, engaja-se em campanhas em defesa dos direitos dos negros, convoca os seguidores para a luta antirracista, homenageia artistas negros, rememora datas importantes para a militância e enaltece o talento e a beleza negra.

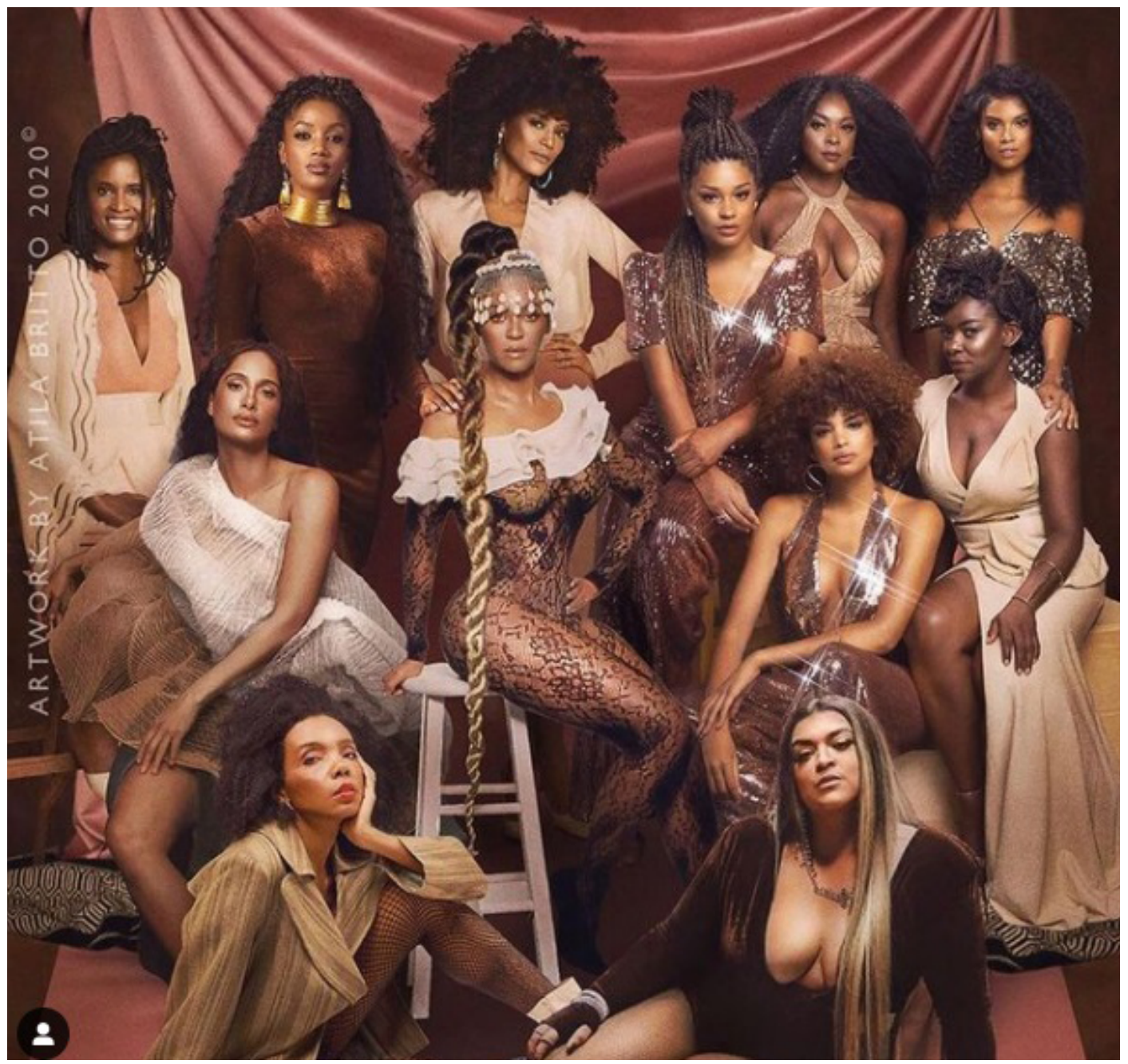

Figura 1: Imagem do post do dia 3 de agosto de 2020

Fonte: Instagram.

Outro elemento que se configura como representativo na constituição de Preta Gil como figura pública é o modo como ela adota um posicionamento de enfrentamento ao padrão de beleza contemporâneo, o que está relacionado com o fato de ela ser uma mulher gorda. Dessa forma, o recorte de peso se 
configura como um outro eixo de opressão que atravessa a constituição de Preta como sujeito e celebridade.

Nesse viés, a figura de Gil distancia-se dos valores estéticos vigentes associados fortemente à branquitude e à magreza - e, consequentemente, daqueles majoritariamente vinculados ao gênero feminino, o que revela, também, a dimensão da igualdade de gênero. Já que o gênero, entendido como uma construção social constituída por meio de processos discursivos e culturais (LOURO, 2008), traz à superfície os tratamentos diferenciados dados aos gêneros masculino e feminino no que se refere a diversas questões, como o padrão de beleza e o significado social do corpo.

Um acontecimento representativo desse posicionamento de enfrentamento ao padrão de beleza foi o lançamento do álbum "Prêt-à Porter", que gerou polêmica pelo fato de a cantora posar nua para a capa e o encarte do CD. Diante da repercussão sobre as fotos, ela declarou no programa "Irritando Fernanda Young", do GNT, que, se fosse magra, aquele "barulho" não teria acontecido. No Carnaval de 2019, Preta lançou a música "Din Din Dom" com a também cantora baiana e mulher gorda, Aila Menezes. No clipe ${ }^{15}$, as artistas convidam para uma dança "sem preconceito" com a presença de homens, mulheres, crianças e idosos.

No Instagram, Preta mostra o que as pessoas não estão "acostumadas" a ver e o que a mídia tradicional não costuma expor no que se refere às mulheres gordas. Ela exibe comportamentos e atitudes até então entendidos como restritos àqueles que se encaixam no padrão de beleza socialmente instituído, como fotos em poses sensuais, além de desafiar os padrões ao usar roupas que são consideradas inadequadas para mulheres gordas, como biquínis, por exemplo ${ }^{16}$.

15 Disponível em: https://www.youtube.com/watch?v=6bAox3yWauk. Acesso em: 10 abr. 2021.

16 Recentemente, a cantora se associou a uma marca de lingerie e lançou uma coleção em prol da diversidade dos corpos com uma numeração que veste do 36 ao 54. Importante ponderar que essa postura também pode ser lida como associada a outro valor, o exibicionismo. 


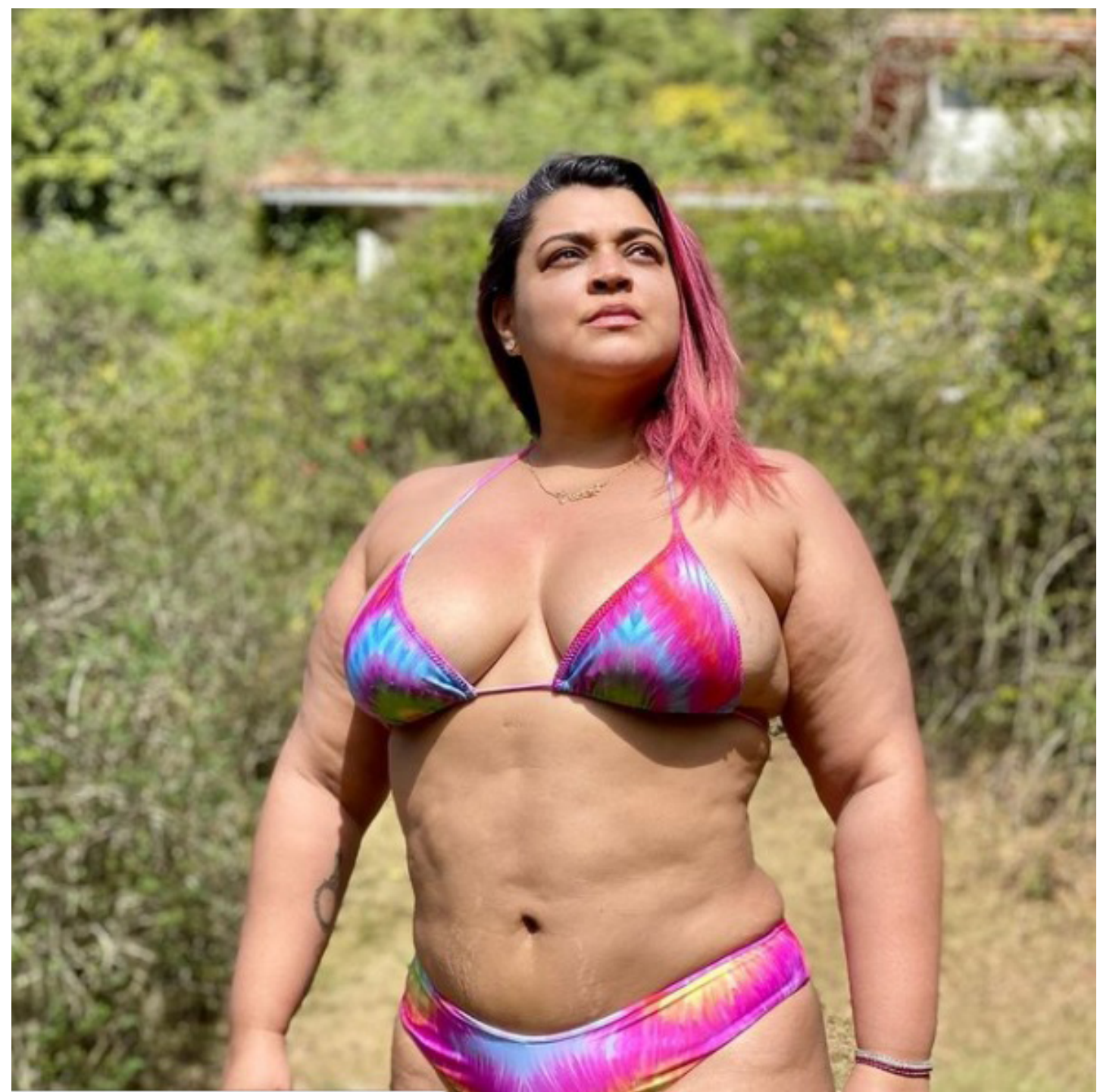

Figura 2: Imagem do post do dia 11 de agosto de 2020

Fonte: Instagram.

Um outro aspecto revelador, em se tratando de valores sociais e que pode ser observado por meio da trajetória de Preta Gil, é a questão da liberdade sexual: a cantora se declara pansexual e é defensora dos direitos $L G B T I+$. Esse posicionamento se reflete em seus posts no Instagram, trabalhos e eventos dos quais participa. Em 2011, foi coroada como a rainha da XV Parada Gay de São Paulo e, em 2019, lançou a música "Só o Amor", em parceria com a drag queen Glória Groove. Para o clipe, que foi denominado pelas artistas como "manifesto musical", 
as cantoras convidaram mulheres trans e a atriz Glamour Garcia, que interpretou uma personagem transexual na novela "A Dona do Pedaço", da qual a música de Preta virou trilha sonora.

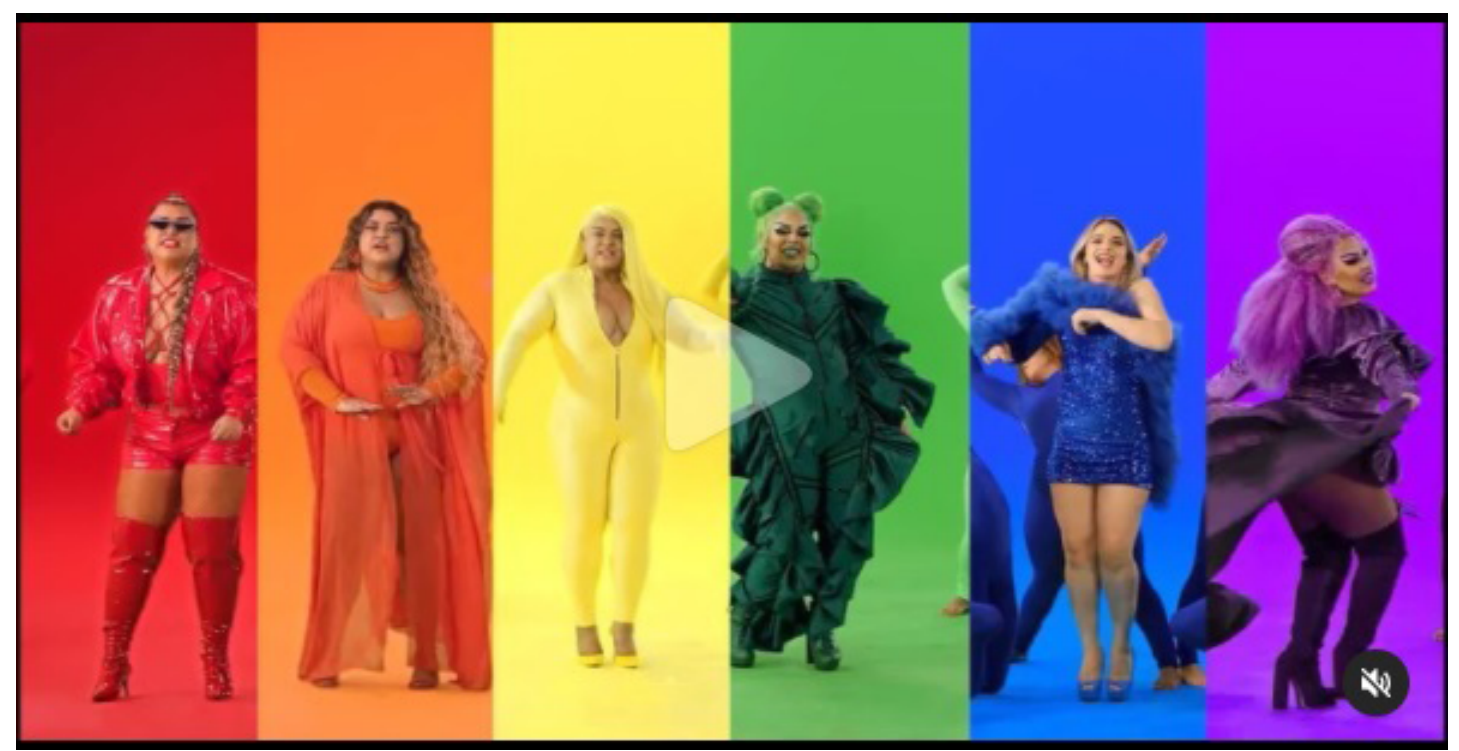

Figura 3: Frame do vídeo do post do dia 28 de junho de 2020 Fonte: Instagram.

Assim, podemos depreender que os sentidos acionados por ela se assemelham àqueles do personagem Félix, da novela Amor à Vida ${ }^{17}$, que protagonizou o primeiro beijo gay entre homens em uma telenovela da Rede Globo de Televisão. "A ocorrência foi muito comemorada tendo em vista o valor dessa representação para a luta LGBT - a luta por direitos, por respeito, por igualdade, mas também por diversidade, os valores-princípio que se revelam nesse acontecimento" (FRANÇA; SIMÕES, 2020, p. 18).

O desenvolvimento da análise evidenciou três eixos que se mostraram representativos da posição assumida por Preta Gil em seu Instagram: raça, peso e sexualidade. Os três eixos articulados são revelados pelo poder hermenêutico dessa celebridade, exibindo sua dimensão acontecimental. Essa capacidade de desvelar sentidos sobre a realidade social está associada ao status de pessoa 
célebre que Preta ocupa e ao posicionamento de enfrentamento a opressões sociais que ela assume. Nesse processo, a leitura acerca dessa celebridade nos leva a associá-la a valores progressistas e emancipatórios, configurando-a, assim, como uma celebridade-resistência a partir do modo como ela se insere na cena pública e o papel que ela exerce na sociedade brasileira.

\section{Considerações finais}

O objetivo deste texto foi analisar como a dimensão acontecimental de uma figura pública (e seu poder hermenêutico) pode configurá-la como o que nomeamos celebridade-resistência, contrapondo-se a opressões sociais e evidenciando valores progressistas. Enfocando a trajetória da cantora Preta Gil a partir de uma abordagem pragmatista e interseccional, analisamos algumas de suas ações materializadas em seu perfil no Instagram. A análise feita a partir dos três eixos de subordinação - raça, peso e sexualidade - nos permite inferir que nessa figura pública está fortemente arraigada a dimensão do enfrentamento e da resistência.

Ao ocupar o seu espaço na cena pública por meio de uma vinculação a grupos socialmente oprimidos, a figura pública de Preta Gil aproxima-se de valores como o de igualdade racial, de gênero e de direitos LGBTI+. No entanto, o seu posicionamento não se limita a se aproximar/representar/evocar esses valores. Ela aciona sentidos que configuram uma posição de embate ao racismo, à desigualdade de gênero, à imposição do padrão de beleza - que fomenta processos de pressão estética e de gordofobia ${ }^{18}$ - e à LGBTfobia.

Tal colocação revela que os valores associados à figura de Preta Gil se constituem a partir de uma oposição a outros traços constituidores da sociedade contemporânea, forjados e sustentados por uma estrutura do ódio que se constitui a partir da categoria do "outro": da alteridade entendida como uma ameaça. 
O "outro" é fabulado como um poder supostamente perigoso ou como algo supostamente inferior; e assim os maus-tratos e o desejo de erradicação subsequente do outro não são reivindicados apenas como medidas desculpáveis, mas necessárias. O outro é aquele a quem alguém pode denunciar ou desprezar, ferir ou matar impunemente. (EMCKE, 2020, p. 14-15, grifos da autora)

A partir desse cenário, é possível associar à Preta Gil o status de celebridade-resistência, uma vez que o seu poder hermenêutico se constitui não só, mas, principalmente, pela maneira como ela se contrapõe a valores que são muito presentes na sociedade contemporânea.

Importante ponderar que nas redes sociais digitais, como o Instagram, as ações são planejadas com base em dados estatísticos - fornecidos, inclusive, pelas próprias plataformas - que orientam as ações dos sujeitos (MEDEIROS, 2016). Diante disso, é preciso não negligenciar a linha tênue que separa as realizações das celebridades como potencialmente atos de resistência e, por outro, como práticas estratégicas com fins mercadológicos.

Faz-se necessário ressaltar, também, que uma mesma celebridade pode representar, evocar e abarcar diferentes valores, já que a constituição da imagem pública não é linear e homogênea. Assim, os quadros valorativos associados à celebridade podem se constituir de forma paradoxal, pois a imagem pública é complexa e mutável (LIMA; SIMÕES, 2017). Em consonância com isso, o objeto estudado neste artigo apresenta-se de forma multifacetada, e a articulação entre celebridade e acontecimento se configura como promissora para abordarmos aspectos do contexto contemporâneo - tais como o enfrentamento de opressões sociais por celebridades-resistência.

Cabe destacar que a análise da face pública de Preta Gil não se esgota nos limites deste artigo. Em análises futuras, será possível, por exemplo, refletir sobre a maneira como o poder de afetação de Preta Gil pode fomentar a circulação de sentidos e a constituição de públicos. Ou seja, dar destaque à passibilidade do acontecimento - a partir da análise das manifestações dos seguidores materializadas nos perfis das celebridades - e pensar o modo como essa figura, 
entendida como celebridade-acontecimento-resistência, pode ser mobilizadora de comunidades acontecimentais que "resultam de um processo de 'aparência' (ou do aparecer) de um público que tem seus vínculos criados e modificados a partir do modo como experimenta, define e problematiza determinados acontecimentos" (MARQUES, 2012, p. 144).

Faz-se necessário ponderar, ainda, que a abordagem dos três eixos de opressão realizada neste texto não visa a esgotar a potencialidade do olhar interseccional sobre Preta Gil. Podemos aventar, por exemplo, que a idade também pode se constituir como um eixo de subordinação, já que a cantora já foi alvo de críticas por ser casada com um homem mais jovem. Diante disso, reforçamos o entendimento de que a "[...] a pesquisa em Comunicação precisa considerar não somente cada um destes eixos separadamente, como os cruzamentos e combinações que são essenciais para a composição identitária diversificada dos sujeitos" (CARRERA, 2021, p. 13). Dessa maneira, novos olhares poderão revelar outros recortes e rearranjos interseccionais constituintes dessa figura pública.

\section{Referências}

CARRERA, F. Roleta interseccional: proposta metodológica para análises em Comunicação. E-Compós, Brasília, v. 24, p. 1-22, 2021.

CRENSHAW, K. Documento para o encontro de especialistas em aspectos da discriminação racial relativos ao gênero. Revista Estudos Feministas, Florianópolis, v. 10 , n. 1, p. $171-188,2002$.

DEWEY, J. A arte como experiência (Tendo uma experiência). São Paulo: Abril Cultural, 1980. p. 89-105. Coleção Os Pensadores.

EMCKE, C. Contra o ódio. Belo Horizonte: Âyiné, 2020. 
FRANÇA, V. R. V. Celebridades: identificação, idealização ou consumo? In: FRANÇA, V. R. V.; FREIRE FILHO, J.; LANA, L.; SIMÕES, P. G. (org.). Celebridades no século XXI: transformações no estatuto da fama. Porto Alegre: Sulina, 2014. v. 1, p. 15-36.

FRANÇA, V. R. V. O acontecimento e a mídia. Galáxia. São Paulo, n. 24, p. 10-21, 2012a.

FRANÇA, V. R. V. O acontecimento para além do acontecimento: uma ferramenta heurística. In: FRANÇA, V. R. V.; OLIVEIRA, L. (org.). Acontecimento: reverberações. Belo Horizonte: Autêntica, 2012b. p. 39-51.

FRANÇA, V. R. V.; LOPES, S. C. Análise do acontecimento: possibilidades metodológicas. MATRIZes, São Paulo, v. 11, n. 3, p. 71-87, 2017.

FRANÇA, V. R. V.; SIMÕES, P. G. Celebridades como ponto de ancoragem na sociedade midiatizada. Revista Famecos. Porto Alegre, v. 21, n. 3, p. 1062-1081, 2014.

FRANÇA, V. R. V.; SIMÕES, P. G. Celebridades, acontecimentos e valores na sociedade contemporânea. E-Compós, v. 23, p. 1-25, 2020.

LANA, L. et al. Experiência. In: FRANÇA, V.; MARTINS, B. G.; MENDES, A. M. (org.). Grupo de Pesquisa em Imagem e Sociabilidade: trajetória, conceitos e pesquisa em comunicação. Belo Horizonte: Selo PPGCom, 2014. p. 141-148.

LIMA, L. A.; SIMÕES, P. G. A construção da imagem pública de Dilma Rousseff durante o impeachment: uma análise preliminar. ENCONTRO ANUAL DA ANPOCS, 42., 2017, Caxambu. Anais [...]. Caxambu: Anpocs, 2017. p. 1-29.

LOURO, G. L. Gênero e sexualidade: pedagogias contemporâneas. Pró-Posições, Campinas, v. 19, n. 2 (56), p. 7-23, 2008. 
MARQUES, A. C. S. Acontecimento e criação de comunidades de partilha: o papel das ações comunicativas, estéticas e políticas. In: FRANÇA, V. R. V.; OLIVEIRA, L. (org.). Acontecimento: reverberações. Belo Horizonte: Autêntica, 2012. p. 21-38.

MEDEIROS, F. F. Fama e engajamento no Instagram: as celebridades e a convocação de públicos. RuMoRes, São Paulo, v. 10, n. 19, p. 158-173, 2016.

QUÉRÉ, L. A dupla vida do acontecimento: por um realismo pragmatista. In: FRANÇA, V. R V.; OLIVEIRA, L. (org.). Acontecimento: reverberações. Belo Horizonte: Autêntica, 2012. p. 21-38.

QUÉRÉ, L. Entre o facto e o sentido: a dualidade do acontecimento. Trajectos, Lisboa, n. 6, p. 59-75, 2005.

QUÉRÉ, L. O caráter impessoal da experiência. In: LEAL, B. S.; GUIMARÃES, C. G.; MENDONÇA, C. M. C. (org.). Entre o sensível e o comunicacional. Belo Horizonte: Autêntica, 2010. p. 19-38.

SIMÕES, P. G. A mídia e a construção das celebridades: uma abordagem praxiológica. LOGOS - Comunicação e Filosofia, Rio de Janeiro, v. 17, n. 31, p. 67-79, 2009.

SIMÕES, P. G. Celebridade e contexto contemporâneo. Galáxia, São Paulo, n. 28, p. $45-57,2014$ a.

SIMÕES, P. G. O acontecimento e o campo da comunicação. In: FRANÇA, V. R. V.; ALDÉ, A.; RAMOS, M. C. (org.). Teorias da Comunicação no Brasil: reflexões contemporâneas. Salvador: EDUFBA, 2014b. p. 173-195. 